\title{
The Pitfalls of Leveraged and Inverse ETFs
}

\author{
Understanding how return volatility adversely affects wealth accumulation is critical
}

BY RODNEY SULLIVAN, CFA

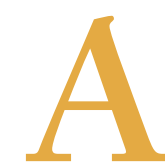

s market volatility has reached historic highs, investors have responded in various ways, including investing in funds that promise to deliver returns that are either a positive or inverse multiple of a stated index.

One example is the growing popularity of leveraged exchanged-traded funds (ETFs). ${ }^{1}$ These so-called ultra funds incorporate leverage in an attempt to double (2X) or triple (3X) market returns or the inverse of market returns. According to Morningstar, globally, there are 145 leveraged ETFs with $\$ 27$ billion in assets. The global financial crisis has seemingly shifted investor attitudes toward financial risk. Although many investors have shunned investment risk entirely, others have responded by increasing investment risk in a move akin to a gambler "doubling down" in the hope of recapturing losses. Such hope, however, does not translate into a solid investment strategy.

Volatility actually erodes returns and wealth accumulation, a fact not commonly understood. Thus, the path that returns take over time has important effects on the long-term total return achieved.

We all know that over a multiyear investment horizon, return (and thus wealth) accumulates by compounding discrete return periods. Less well known is the fact that as the variability of returns increase, compound return decreases. So, the higher the volatility over time, the lower the wealth accumulation to the investor. In this way, return volatility can actually punish investors over the long run.

A simple example will help clarify. If a -10 percent return in one year was followed by a 20 percent return in the next year, the total return to the investor over two years would be 8 percent. Interestingly, over the same period, a $2 X$ fund would return not the expected 16 percent but only 12 percent. As this example shows, the return-volatility relationship matters for all returns but is especially important when leverage is involved.

Leveraged funds will tend to underperform the underlying index multiple and at times can vary significantly from it. The impact on the return difference increases as the multiplier and volatility increase. While leveraged fund returns over time will likely be less than their stated multiple, the volatility of those returns will be as high or even higher. In other words, a fund promising to double the return on a particular index will likely return less than twice the index in the long

1. See Private Client Corner ("The Cutting Hedge") in the March/April 2009 issue of CFA Magazine. run, even though the volatility or risk of those returns will be two times greater-or even more. In short, with a $2 X$ fund, investors receive at least twice the risk of the index but less than twice the return. Clearly, this is not a desirable outcome for investors, yet the drag imposed by return volatility makes such a result inevitable.

The implication is that the returns from ultra funds over the long run are not very predictable. Thus, leveraged funds offer poor long-term hedging capability. Note that the investor holding period for the leveraged fund is a critical factor. An investor who holds a leveraged fund for a day or less will likely receive the stated multiple return, but a longer holding period will mean greater unpredictability imposed by the drag from return volatility. Long-term risks cannot be managed or hedged with leveraged funds. Prudent investors, therefore, should consider the use of leveraged funds with great caution, especially for periods longer than a day.

Moreover, in striving to meet their multiple mandates, leveraged funds get their leverage via derivative instruments. The prices of derivative contracts do not necessarily move in tandem with the underlying cash market securities. The net effect is that ultra funds can race ahead or lag behind the index over short periods. There is also a drag from the direct or indirect cost of borrowing used in implementing the leverage.

Recent market volatility demonstrates how the returns of these funds can deviate from their stated multiples. According to data from Bloomberg, during the 12-month period ending January 2009, the return of ProSharesUltraShort International, with a mandate to return twice the inverse return of EAFE, posted a positive return of about 66 percent while EAFE returned -45 percent. In other words, UltraShort International investors received about $1 \mathrm{X}$ the inverse performance rather than the expected $2 \mathrm{X}$ result. Another example comes from the downtrodden real estate sector. The Dow Jones Real Estate Index fell nearly 60 percent over the 12 -month period ending February 2009. The goal of the ProShares UltraShort Real Estate ETF is to return double the inverse return of this index. Unfortunately, however, instead of rising 120 percent, as might be expected, the fund actually declined 21 percent during the period.

In sum, leveraged and inverse ETFs do not constitute solid investment or hedging options for the long-term investor. The returns on these funds are persistently dragged down by volatility and other factors and thus can run away from the stated return multiple of the underlying index.

Rodney Sullivan, CFA, is head of publications at CFA Institute and associate editor of the Financial Analysts Journal. 